\title{
Article
}

\section{Young tourists' experiences at dark tourism sites: Towards a conceptual framework}

Kerr, Mary Margaret, Stone, Philip and Price, Rebecca H

Available at http://clok.uclan.ac.uk/35214/

Kerr, Mary Margaret, Stone, Philip ORCID: 0000-0002-9632-1364 and Price, Rebecca H (2021) Young tourists' experiences at dark tourism sites: Towards a conceptual framework. Tourist Studies, 21 (2). pp. 198-218. ISSN 1468-7976

It is advisable to refer to the publisher's version if you intend to cite from the work. http://dx.doi.org/10.1177/1468797620959048

For more information about UCLan's research in this area go to http://www.uclan.ac.uk/researchgroups/ and search for < name of research Group>.

For information about Research generally at UCLan please go to http://www.uclan.ac.uk/research/

All outputs in CLoK are protected by Intellectual Property Rights law, including Copyright law. Copyright, IPR and Moral Rights for the works on this site are retained by the individual authors and/or other copyright owners. Terms and conditions for use of this material are defined in the policies page. 


\section{Young Tourists' Experiences at Dark Tourism Sites: Toward a Conceptual Framework}

\section{Introduction}

Dark tourism has become an internationally recognized taxonomy denoting touristic travel to sites of or associated with death and 'difficult heritage' (Hartmann, 2014; Lennon and Foley, 2000; Stone, 2006, 2014; Stone et al, 2018). While dark tourism aimed at adults reminds them of past tragic fights, faults, and follies, thousands of young tourists also consume inherent memorial messages at dark tourism sites. This paper addresses these unnoticed childhood encounters, about which scholarly discourse remains conspicuously silent. Poria and Timothy (2014: 93) argue that "children's voices ought to be heard if the aim of scholarly inquiry is to conceptualize the tourist experience more comprehensively and responsibly." Accordingly, we introduce the topic with a child's own words.

One morning in 2002, Aaron, the young son of one of the authors, slid an envelope under the author's door. Addressed to "Daddy and Mummy," the envelope contained a memento mori [reminder that one shall die] from a young boy coming to terms with mortality:

To Daddy and Mummy

I like you very much and I wanted to live with you all the time but when you die I won't forget about you.

Love

Aaron

$\operatorname{xxxxxxxxxxx}$

In fact, many young children think about death, although adults may not realize it. The reality is this. . Children encounter death often. Their awareness with death and dying may come from real-life and/or vicarious experiences. Whether their familiarity comes from video games, children's literature, cartoons, feature films, while watching the evening news, or from personal experience in their very own homes and/or communities, one thing remains constant: Death is tangible (Perkins and Mackey, 2008:13).

Dark tourism, with its death narratives and fatality encounters, also makes death 'tangible'-certainly within popular culture (Penfold-Mounce, 2018; Walter, 2009). The remembered dead exert agency while 'edutaining' tourists, occupying touristic traumascapes roamed by children as well as adults (Roberts, 2018; Stone, 2012; Stone and Sharpley, 2008; Stone et al., 2018; Walby and Piché, 2015). Despite taxonomical debates between the term 'heritage tourism' and 'dark tourism' (Light, 2017), remembrance through dark tourism, offering a selective interpretive voice, records tragedy across time, space, and context, and subsequently causes one to reflect on both places and people. Hence, different cultural, political, and linguistic representations of dark tourism and varying revelatory experiences are complex and multifarious for younger tourists (Kerr and Price, 2018).

Young tourists' experiences within specific dark tourism encounters remain largely unstudied. That is especially pertinent considering their developing notions of death, their vulnerability, and their increasing visitation to places of the remembered dead (Kerr and Price, 2016). Thus, we propose an original conceptual framework that provides a 'scholarly route map' for the academic interrogation of young tourists' experiences at dark tourism sites, with a focus 
on sites commemorating death (i.e., heritage sites). We recognize that young tourists also visit dark sites known for their entertainment, but that experience requires its own conceptualization. Although a position paper cannot cover every conceptual or practical eventuality, we offer a judicious framework that shines scholarly spotlights on pertinent areas worthy of examination.

Ultimately, our paper uncovers potential research pathways that situate young tourists and their visit dynamics at the core of dark tourism research. Firstly, however, we review 'youn tourists in tourism research' as a foundational basis for our subsequent 'young tourists at dark tourism sites' conceptual framework. For brevity, we use 'young tourists' to refer to those ages 5-14, while denoting developmental differences that further define these subgroups.

\section{Young Tourists in Tourism Research}

Over 35 years ago, in Annals of Tourism Research, then-editor Nelson Graburn called for the expansion of social anthropology within tourism studies and, specifically, for the inclusion of young tourists within tourism research. Graburn noted:

Most lacking, perhaps, are studies of the effects of tourism on the historical, natural, and geographical awareness of children: the trajectory and interrelationship of their touristic and recreational experiences, and the relations of these to their adult life styles and to their subsequent recreational and vocational behaviors (1983: 3).

More recently, noting Graburn's charge to the field, Small (2008) observes that studies of children and childhood in tourism remain largely absent. This conclusion comes despite some early studies focusing on children's influences on parental decision-making within travel and tourism, and children's influence on adult tourism experiences (e.g., Tagg and Seaton, 1994). Other research stresses young tourists as a distinct tourism industry market segment (Ryan, 1992; Swarbrooke and Horner, 1999). This focus on children as consumers - or 'toddler tourism' - and its implications for marketing strategy and buyer motivations, continues with studies examining children as co-decision makers in holidays and leisure (e.g., Cicero and Teichert, 2018; Ji et al., 2014; Schänzel and Carr, 2016; Wu and Wall, 2017).

Meanwhile, some researchers imagine the multiple ways in which children might make meaning of a tourism experience. For instance, Cullingford (1995) begins the task of examining young tourists' actual holiday experiences by suggesting that they might vary as widely as those of adult tourists. Likewise, Poria et al. (2005) argue that industry operators should improve tourist experiences that enhance knowledge and examine relationships between young tourists' geographical knowledge and travel experiences. Similarly, Elmi et al. (2020) explore young tourists' representations of travel and offer a comparison between what they remember and what they desire with regard to tourism.

Young tourists are also a key feature of the general tourism product and experience. This phenomenon is particularly so in marketing and consumer behavior, family tourism, or social tourism (Minnaert, 2014; Schänzel et al., 2012). Marketing to young tourists is also noticeable at large and well-traveled dark tourism destinations, which become increasingly 'kitschified' (Potts, 2012). Importantly, however, there are potential issues of meaning-making within dark tourism. Specifically, the tourist experience depends on the availability and communication of narratives and stories. Much of this has depended on host sites as the main designers and promoters of touristified narratives, whilst the role of the tourist is often ignored in the process. Therefore, an 
issue of co-constructing meaning depends on tourist's involvement, willingness, and ability to actively participate in the storytelling (Chronis, 2012).

Yet, much of the co-construction of meaning is focused on adult experiences, and children's meaning-making of heritage remains overlooked. Despite increasing interest in tourist experiences and meaning-making (Bosangit et al., 2015), the tourism research agenda largely ignores young tourists (Frost and Laing, 2017; Poria and Timothy, 2014; Small, 2008). As Mooney et al. (2017: 106) protest, "children are relegated to the side-lines, as if unworthy of being in full view because their purchasing power relies on influencing their parents."

Why have researchers been reluctant to study young tourists? To begin, tourism training programs typically do not adopt a 'post-disciplinary' and child-focused approach (Stone, 2011). As a result, researchers may lack requisite skillsets, disciplinary knowledge, or research partners to enter the complex world of young tourists (Coles et al., 2009). Moreover, laws governing ethical research with children require researchers to submit clearances and document suitable data collection methods in order to minimize risk. Obtaining informed consent can be arduous and time-consuming. Faced with these additional constraints, scholars hesitate to engage children in their research protocols (Poria and Timothy, 2014).

Despite the barriers, emerging studies examine young tourists' experiences within dark tourism (Kerr and Price, 2018). Indeed, studies have begun to capture mortality moments of young tourists in some dark tourism environments, such as 9/11 sites, Holocaust exhibits, and war memorials (Kerr et al., 2017b; Price, 2018;Price and Kerr, 2018). Israfilova and KhooLattimore (2018) examine the educational importance of dark tourism, focusing on young tourists' experiences after their exposure to dark sites. They go on to suggest that visits to a thanatological attraction enlighten students and motivate them to study history as well as develop a deeper sense of patriotism. However, the cultural context of young tourists' behavior at memorials and other difficult heritage sites is still not well understood. Emotional aspects are also explored by Martini and Buda (2020), who within a framework of 'emotion and affect' suggest that while most young tourists felt sorrow at dark tourism sites, others enjoyed the experience for its fascination and the chance to see places with 'their own eyes.'

Indeed, 'with their own eyes' might characterize a recent development in tourism research. Canosa et al. (2019) propose an infusion of principles and practices from childhood studies into tourism research. Methods from childhood studies offer direct access to children's thoughts, experiences, and motivations. Recent developments in childhood studies embrace children's voices and empower children to research their own experiences. Such research prioritizes children's observations and experiences (Canosa et al., 2019; Canosa et al., 2016; Kellett, 2005, 2010; Prout and James, 1997; Woodhead, 2008), and in so doing could provide valuable first-hand information about how children view tourist experiences as consumers. Taking into account these principles, we continue our review of the literature by examining the complexities of childhood and adolescence in dark tourism.

\section{Dark Tourism and the Complexities of Young Tourists}

To fully examine child dark tourism one must consider three complexities that characterize young tourists: what they comprehend about death, why they visit dark sites, and how they explore destinations. The first complexity emerges when one considers that dark tourism frameworks presume a mature adult understanding of death. However, "children who have not reached a mature understanding of these death concepts may find it difficult to engage 
with and understand death-related material presented in a museum exhibit" (Patterson, 2007: 58). Even when children understand death intellectually, they may not be emotionally ready to cope with it, as Israfilova and Khoo-Lattimore noted (2018).

Children must cognitively master five subconcepts to attain a mature understanding of death. Universality refers to the concept that all living creatures die (Speece and Brent, 1984). Children's initial understanding of this concept may express itself in terms of plants or insects but not humans. Finality, or irreversibility, conveys the notion that after death, a living thing cannot come back to life (Rosengren et al., 2013). For example, children may believe that humans come back to life because make-believe characters do.

Non-functionality describes the inability of the dead to engage in functions such as speaking, hearing, and thinking. For example, young children attempt conversations with mummies or taxidermy displays. Inevitability is an understanding that death is unavoidable. Adults witness this confusion when children propose escape plans for victims commemorated at memorials. Causality connotes different causes of death, including illness, accidents, and intentional acts. Scholars often refer also to a sixth concept, personal mortality, or the acknowledgment that one's own death is inevitable and unavoidable (Bianucci et al., 2015). Adolescents' awareness of personal mortality can evidence itself in death anxiety (Croom et al., 2018).

Each child's developmental timeline is influenced by their cognitive development and ability to understand abstract concepts. Children's books, films, and television clarify or confuse their thinking (Gutiérrez et al., 2014), as do 'thana-technology' (Sofka, 1997, 2009), social media, and internet gaming. Personal experiences with the death of a pet or extended family member can accelerate children's comprehension of death (Hunter and Smith, 2008). Although researchers cannot pinpoint exactly when children learn each concept, Table 1 offers a general timeline, with implications for child dark tourism.

\section{[Insert Table 1 here]}

A second childhood complexity arises when considering why young tourists visit dark tourist sites. Contemporary dark tourism theories focus on what motivates adult visits, but "the general field of tourism research and the specific field of tourism motivation seem to lack a systematic interest in children's motives" (Larsen and Jenssen, 2004: 45). For example, teachers - not students-typically plan itineraries for school trips (Cooper and Latham, 1988). As Walter (2009: 53) observes, "children find themselves being taken to battlefields by teachers and parents, just as children in this and other cultures find themselves being taken to church or temple."

As Shavanddasht and Schänzel (2019: 308) suggest, "there is an urgent need to understand adolescents' needs, motivations, and role in the tourism industry, particularly the factors that may affect their tourism satisfaction." Arguably, this charge takes on enhanced importance within a dark tourism experience, where a young tourist's motivations may shape how they respond to a particular traumascape in childhood and, in turn, influence their future travel decisions.

A third complexity reveals itself when one observes how young tourists explore sites in uniquely youthful ways. Young children's play at dark sites may reflect their immature understanding of the death and destruction remembered there. Stevens and Frank (2015) observed, for example, a young child jumping on and off rocks at the National AIDS Memorial. 
Reenacting death through more elaborate play may reflect an older youth's comprehension of the events or their desire to 'assert ownership' (e.g., Knudsen, 2011). To illustrate, Bowman and Pezzullo (2010) and Carr (2011) observed young tourists playing war at battlefields and abandoned bunkers. Similarly, Roche and Quinn (2017) watched young tourists play on the structures and rubble of former battlefields. Yet, youthful play may provoke censure by adult critics. Conflicting views on children's behaviors emerged in Cui et al.'s 2019 analysis of visitor comments at the Memorial of the Victims of the Nanjing Massacre. Some visitors viewed young tourists' actions as annoying, disruptive, and disrespectful. Indeed, notions of respect and morality are inherent at memorial tourist sites, and play at such sites exposes not only design and interpretation issues, but also conflicts of values, beliefs, and deep-seated feelings (Price and Kerr, 2018). As Sutcliffe and Kim conclude:

Research tends to examine how accompanying adults interact with children, teach children about appropriate behaviour in heritage/museum venues, or types of exhibits favoured by children. These approaches assume children to be adults in the making, and rarely approach the child's visit in the way that a child likely would, and that is from the aspect of play. (2014: 335)

Due to the aforementioned complexities, current dark tourism theories do not illuminate young tourists' experiences. Therefore, we set out to build a framework that encourages more relevant paths for studying young tourists.

\section{Young Tourist Experiences at Dark Tourism Sites: An Initial Conceptual Framework}

As McCabe (2005: 103) observes, "to develop a meaningful engagement within the sociology of tourism with tourists, we will have to recognize the cultural and interactional contexts in which we engage with our subjects." Mindful of the complexity of these contexts in childhood, we first examined hundreds of archived tributes and post-visit comments authored by children and youth at two 9/11 sites, two Holocaust museum exhibits, and a medical history museum (Croom et al., 2018; Kerr and Price, 2018; Kerr et al., 2017a; Kerr et al., 2017b; Kerr et al., 2016). The texts and artwork shed light on how children of different ages interpreted and reacted to death and dying. We also observed the impact of adult influences on children's developing understanding of death in dark tourism contexts (Kerr and Price, 2018).

Mindful that children and youth should increasingly take a more active research role, as "experts of their own lives" (Pinter and Zandian, 2014: 64), we next sought school partnerships to engage youth in writing, photographing, and discussing their own dark tourism experiences. These partnerships allowed us to travel on a day or overnight excursion while observing and interacting with youth ages 11-15 years (302 total). We deemed such collaborations necessary to "enter the field, that is, to mingle with their research participants, breathe and feel the same air, taste the same food, and hear the same sounds" (Matteucci and Gnoth, 2017: 20). The youth participated in motorcoach interviews, wrote post-visit comments, and took photographs (Burns, 2018; Price, 2018).

What emerged from our 'mobile ethnography' are three additional influences that frame our conceptualization of young tourists' experiences. Altogether, the framework shown in Figure 1 encompasses a) children's prior understanding of death, b) preparation before a visit, c) site attributes, including interpretation, and d) dynamics of the visit. 
[Insert Figure 1 here]

\section{Preparation for a Visit}

While traveling, we interviewed site managers, tour guides, museum interpreters, parents, and educators. These conversations resulted in the next part of the framework: the preparation a young tourist receives before visiting a dark tourism site, as shown in Figure 2.

\section{[Insert Figure 2 Here]}

Informal preparation includes how adults explain tragedy to children. Intentionally or not, family conversations may shape children's experiences at dark sites (Frost and Laing, 2017; Kerr and Price, 2016, 2018). Our archival studies confirmed the influence of such family dialogues. Many comments at a Holocaust museum referred to family conversations, such as this one: "I have grown up, hearing about the Holocaust my whole life. I lost many of my family members to the Holocaust."

Moreover, family religious discussions affect children's understanding and beliefs about deadly events (Rosengren et al., 2014). Gutiérrez et al. (2014: 60) note that in both European and American contexts, "parents responded not just with information but also with reassurance when their children asked questions about death, with religious reassurance figuring especially prominently." As expressed by a $9^{\text {th }}$-grade girl who visited a genocide memorial, "objects strengthened my feelings of sadness towards people who were victims of this event. This trip also enhanced my perceptions about those who do not have faith and lack good moral habits" (Israfilova and Khoo-Lattimore, 2018: 8).

Social media posts or television also influenced children's meaning-making (Falk and Dierking, 2018). In this context, dark tourism sites offer online activities, videos, and readings (e.g., the U.S. Smithsonian Latino Center's Theater of the Dead and the Greenwich, UK Royal Museum's Death in the Museum Trail) — an influence documented by Roche and Quinn (2017), who note that a site's media and social media images inform pre-teens' preconceptions of dark tourism.

While formal instruction specifically about death and dying is uncommon in some countries (King-McKenzie, 2011), teachers may require students to read about the deaths commemorated (Kucan et al., 2017; Lovorn, 2012). When done well, such instruction increases engagement. For example, students who had studied an 1889 flood disaster eagerly asked many questions, while poring over artifacts and exploring gravestones with intense interest. In contrast, poor preparation reveals itself in children's visitor comments such these visitor log entries collected at the U.S. Holocaust Memorial Museum:

- "What they teach us at school are just numbers, but this showed me the stories."

- "When I am at school my teachers have never told me about this. Once I go back I'm going to teach my class about all of this."

Formally or informally, how a nation prepares its children - how it defines the 'nationhood' that binds its people together - is reflected in what, how, when, and whom it chooses to memorialize. Therefore, young tourists visiting dark tourism destinations may experience a reinforcement of values that they are expected to uphold (Park, 2010). 
In summary, dark tourism researchers have yet to explore how, when, and where young tourists learn about dark sites or events, even though these prior messages may be more influential than the site itself (Roche and Quinn, 2016). As a starting point, researchers might consider comments young tourists record on social media and visitor book pages (Kerr et al., 2017b). Collaborations with schools offer a more comprehensive view of preparation. Our own collaborations, observations, and visitor comment analyses led us to a third, complex component of our framework - the site, including its exhibits and interpretation, as shown in Figure 3.

\section{[Insert Figure 3 Here]}

\section{Site and Interpretation}

Site attributes influence the tourist experience (Virgili et al., 2018). Our observations captured young tourists exploring memorials, Holocaust and war museums, cemeteries, and exhibits focused on death and disaster (Burns, 2018; Price, 2018;). These 'physical contexts' (Falk \& Dierking, 2018) are incorporated as site type, exhibits, and interpretation.

In dark tourism, the types of sites may include museums, visitor attractions, memorials, cemeteries, battlefields, penitentiaries, and concentration camps - each with many spaces for children to explore. Moreover, children and youth who visit a site during a memorial event honoring a loved one would likely experience this as a dark event (Laing and Frost, 2013). In addition, temporary 'dark exhibits' might create a dark tourism experience in an unexpected venue. "The Bog People" exhibition (of mummified human bodies) hosted by a natural history museum provides one example (Patterson, 2007). The Indianapolis Children's Museum offers a permanent exhibit, "The Power of Children," where live theatre communicates the stories of children, including Ryan White, who died of HIV/AIDS. To enhance the experience, the exhibit includes White's completely recreated bedroom showing his bed, toys, and clothes (Simon, 2009).

Such visual exhibits merit special consideration. Because younger children may not comprehend abstract ideas or text in interpretative panels (Moscardo et al., 2007), they often focus on visuals, such as films or photographs. Yet, cognitive psychology research reveals that disturbing images can have an emotional impact on children of any age. Young children, in particular, may view geographically or temporally remote images in videos as present-day threats (Hirsch and Holmes, 2007). This research is pertinent to understanding the young tourist experience because news videos figure prominently in some museums. Similarly, photographs could upset young visitors, as an adult visitor recalled in a Holocaust museum: "Today I saw a little boy sobbing over a picture of other little boys, his age, emaciated and being experimented on" (United States Holocaust Memorial Museum visitor log, November 1, 2018).

At present, we have only such anecdotal reports to tell us how young tourists feel when confronted with death and suffering at sites where the victims include children. Examples include the Oklahoma City Bombing Memorial and the Pentagon 9/11 Memorial, where the designs highlight each victim's age. Also, consider the display of child remains at the genocide memorial site at Ntarama in Rwanda (Caplan, 2007) and the Roman Dead exhibit of child skeletons at the Museum of London Docklands.

While exhibits may frighten some young tourists, others may prefer intense images. Walter (2004: 619) records in his study at the Korperwelten/Body Worlds exhibition one youth's comment that the exhibit "is very educational but there should be more blood and gutsy stuff it is 
not very scary or evolting [sic]." Walter (2004: 619) further notes that "though several guestbook entries by those coming without children make predictions of children having nightmares, comments about actual pre-adolescent children refer to their positive engagement in a factual, rather than a gothic, gaze."

Further complicating the very young 'tourist's gaze' (Urry and Larsen, 2011) are accommodations for individuals with disabilities. At dark sites, short captions intended for those with visual impairments may project large-print, grim words that young children can read (e.g., BABY DEAD at a kidnapping exhibit). Moreover, placing some objects at lower heights to accommodate wheelchair users inadvertently situates gruesome artifacts directly at a young child's eye-level. These immediately accessible artifacts become particularly salient for young tourists, because "children naturally seek opportunities to explore and learn through their senses" (Shaffer, 2016: 43).

The interpretation adopted by the site also influences young tourists' experiences. For example, they may find no interpretation (e.g., London's 7 July bombing memorial), or listen to tours written solely for adults (see Walter, 2004). Conversely, when young tourists visit the Anne Frank House Museum and Memorial in Amsterdam, they read and hear a child's words. A similar child-centered interpretation awaits young tourists at 'Daniel's Story,' the children's exhibit of the U.S. National Holocaust Memorial. Notwithstanding well-rehearsed arguments of authenticity within dark tourism (Sharpley and Stone, 2009), site interpretation (or lack thereof) in this context warrants more research. For example, Roche and Quinn (2016) found that young tourists most easily recalled items that a tour guide specifically pointed out or described with hand gestures. Observations during such school trips informed the framework's final section, dynamics of the visit, as illustrated in Figure 4.

[Insert Figure 4 Here]

\section{Dynamics of the Visit}

Fluctuating influences that may be present during a visit include the itinerary, the child's touring group membership, and rules or norms. Adults and children mingle together as they coconstruct meaning at dark sites. For example, Roche and Quinn (2017) argue that social interactions with their peers and tour guides inform young tourists' preconceptions of dark tourism. Similarly, Burns observed this co-creation process taking place in her study of youth visiting dark sites:

Over the course of the trip, students created a community of learners, sharing their learning and working together to make meaning of the experience. . .students also learned to 'read' the space they occupied and identified and complied with implicit behavioral norms. (2018: iv-v)

Indeed, other situational aspects of a visit include the behavioral rules and norms, whether conveyed implicitly or explicitly by signage, staff, or other visitors. In a recent example, public comments revealed strong convictions about young tourists' demeanor at memorials. These comments appeared after a photograph of young children clambering on a memorial statue went viral on a social media site (Price and Kerr, 2017).

A young tourist's itinerary undoubtedly influences their experience. Optimally, young tourists receive instruction designed by a site's education staff (see Marcus et al., 2012). 
However, thousands travel on overnight school excursions with packed itineraries that may limit their visit time to less than one hour, thereby reducing their access to on-site educational programming (see Burns, 2018; Price, 2018). As a school trip director explained: "We do so many things, but it's just a bird's-eye view. You know... we see a piece of this, a snippet of that" (C. Greene, 2015, personal communication). In such instances, young tourists may receive minimal interpretation, leaving them to comprehend exhibits about death and dying on their own.

In summary, multiple sources-including archives, observations, interviews, and literature reviews-allowed us to construct an evolving conceptualization of young tourists' encounters with death and dying. We now turn to the implications of this new conceptual framework.

\section{Implications for Future Research}

As Picard and Robinson observed, we "need an understanding of tourists as persons and how they encounter, receive, respond, and react to the effective change in conditions which tourism ultimately entails. This is where things become complex" (2012: 23). Given the rise in dark tourism publications, one might conclude that dark tourism research has already identified these complexities. However, when one scrutinizes this literature, one sees that children 'as persons' are largely overlooked. Adult theories and research methods cannot explain their encounters because the developing cognitive, emotional, physical, and interpersonal attributes of children and youth do not resemble those of adults.

Moreover, teachers and parents often choose itineraries and, in so doing, convey their own knowledge, beliefs, and norms. Once younger visitors arrive at a dark tourism site, they often encounter adult-oriented interpretation, exhibits, and perspectives. Adults at a site may communicate strong beliefs about how younger tourists should behave. Yet, young tourists may best experience a site through play, touch, make-believe, or other 'forbidden' behaviors.

For reasons such as these, young tourists' encounters require novel conceptualizations and data collection approaches that recognize children as persons. To this end, our framework seeks to accelerate and deepen our understanding of young tourists' experiences at dark tourism sites. As Dallari and Mariotti conclude, "tourism for children and adolescents continues to be a field where it is difficult to obtain reliable and trustworthy data... Undoubtedly, much still needs to be done to produce a valid and universal methodology to tackle this phenomenon" (2016: 21).

How might research methodology be adapted to explore the intersecting influences cited in the framework? First, researchers hesitant to work directly with young tourists can access dark tourism site archives, which include children's art, letters, tributes, and post-visit comments (see Kerr et al., 2017b for specific methods). As evidenced in this paper, these collections shed light on meaning-making, recollections, evaluations, and emotional expressions. Content analysis of artifacts (guided by the concepts articulated here) does not always require formal human subjects protection review, increasing its appeal to some.

Secondly, we acknowledge the importance of selecting methods suitable for the child's age, as highlighted by Khoo-Lattimore (2015) and others. This approach would take into account children's different understandings of death concepts. As illustrated in this paper, tourism researchers should adopt also multiple measures to optimally engage young tourists in sharing their experiences (Kerr and Price, 2018; Israfilova and Khoo-Lattimore, 2018).

Thirdly, our framework includes influences that are present before, during, and even after a trip (Falk and Dierking, 2018). To capture these influences necessitates phased data collection 
across time. Based on our own experience, we concur with Roche and Quinn (2016) that such a phased approach also allows children to become more comfortable with adult researchers.

Finally, we endorse the approaches of those working in childhood studies, who recognize young tourists as capable of exploring their own experiences. Our own team now includes youth members who co-design measures, collect data, and interpret findings.

\section{Implications for Practice}

The framework presented here has direct utility for site managers and interpreters who seek to engage young tourists. An example appears at the Flight 93 National Memorial commemorating victims hijacked on September 11, 2001. There, interpreters struggled to explain the terrorist attack to young tourists. By inviting youth to visit the site and give feedback on preliminary drafts of interpretive materials, the staff designed a child-friendly 'Junior Ranger Program' that now engages young tourists in age-appropriate, multi-sensory activities. In another example, the staff considered young children's vulnerability to visual images. The result was the decision to limit video footage to one highly placed monitor and to move grim artifacts out of young children's immediate eye-level.

A more recent example took place at the National Pentagon 9/11 Memorial. This site receives 750,000 visitors per year, most of whom are on school trips. Using the framework, 13 year-old researchers conducted pre- and post-visit interviews and surveys to assess school trip visitors' preparation and their perceptions of the site and interpretation. Following their trip, the youth analyzed their data and presented recommendations on how to improve the youth visitor experience.

Without such research-practice partnerships, destination managers, interpreters, and even vendors may miss opportunities to engage younger tourists. Moreover, young tourists' negative experiences can influence their future motivations to avoid particular sites. Uninformed about their childhood experiences, the dark tourism industry may lose them as adults.

\section{Conclusion}

Importantly, a child's understanding of death and dying develops as the child matures. This less-than-fully developed understanding, coupled with emotional immaturity, often frames young tourists' experiences within dark tourism. Indeed, Aaron (whose letter to his parents introduced this paper) welcomed his father home from a research visit to Auschwitz-Birkenau. After hearing an explanation of Auschwitz - the people murdered and the nature of atrocities committed there - Aaron (then six years old) simply replied, "Daddy, can you hear them scream?" Of course, dark tourism is filled with the "screams' of the significant dead. How we present or represent the tragic dead to young tourists remains problematic. Consequently, the framework and its parameters beckon scholars to explore complex factors that influence, inform, and have consequences for young tourists' visits at dark tourism destinations. Indeed, the task for future cultural tourism and heritage scholarship is to utilize the framework or parts thereof, and reconnoiter research avenues illuminated by our agenda.

Hindered by the general lack of research on young tourists at dark tourism sites, we recognize the inherent risk in articulating a conceptual model. Nevertheless, we heed Veal's (2017: 76) advice that "a conceptual framework need not be a straitjacket; it can be a flexible, evolving device." It is our hope that those who embark on research with young tourists will 
adapt and refine this model to include differences among them and among the sites that they visit.

This framework proposes influences on a young tourist's experience at a dark tourism destination. It simultaneously calls on scholars to identify how best to pursue their questions, not with traditional adult tourism research methods, but rather with innovations suitable for engaging young tourists, perhaps even as researchers themselves. In doing so, the curious will find a rich landscape of new methods and discoveries that not only benefit the tourism field but also enrich these long-neglected childhood encounters. 


\section{References}

Bianucci R, Soldini M, Di Vella G, et al. (2015) The body worlds exhibits and juvenile understandings of death: Do we educate children to science or to voyeurism? Clinical Therapeutics 166(4): e264-268.

Bosangit C, Hibbert S and McCabe S (2015) "If I was going to die I should at least be having fun": Travel blogs, meaning and tourist experience. Annals of Tourism Research 55: 114.

Bowman MS and Pezzullo PC (2010) What's so "dark" about "dark tourism"? Death, tours, and performance. Tourist Studies 9(3): 187-202.

Burns L (2018) Overnight school trips: An overlooked phenomenon. PhD Thesis, University of Pittsburgh, US.

Canosa A, Graham A and Wilson E (2019) Progressing a child-centred research agenda in tourism studies. Tourism Analysis 24(1): 95-100.

Canosa A, Moyle BD and Wray M (2016) Can anybody hear me? A critical analysis of young residents' voices in tourism studies. Tourism Analysis 21(2-3): 325-337.

Caplan P (2007) "Never again": Genocide memorials in Rwanda. Anthropology Today 23(1): $20-22$.

Carr N (2011) Children's and Families' Holiday Experiences. Abington: Taylor \& Francis.

Cicero L and Teichert T (2018) Children's influence in museum visits: Antecedents and consequences. Museum Management and Curatorship 33(2): 146-157.

Coles TE, Hall CM and Duval DT (2009) Post-disciplinary tourism. In: Tribe J (ed) Philosophical Issues in Tourism. Bristol: Channel View Publications, pp.80-100.

Cooper C and Latham J (1988) English educational tourism. Tourism Management 9(4): 331334.

Cui R, Cheng M, Xin S, et al. (2019) International tourists' dark tourism experiences in China: The case of the memorial of the victims of the Nanjing Massacre. Current Issues in Tourism, 23(12): 1-19.

Cullingford C (1995) Children's attitudes to holidays overseas. Tourism Management 16(2): 121-127.

Croom AR, Squitiero C and Kerr MM (2018) Something so sad can be so beautiful: A qualitative study of adolescent experiences at a 9/11 memorial. Visitor Studies 21(2): 157-174.

Dallari F and Mariotti A (2016) Children in Tourism: a fresh perspective? The experience in Italy, from summer camps to the Seninter project. Tourism Review (10).

Elmi B, Bartoli, E, Fioretti C, et al. (2020) Children's representation about travel: A comparison between what children remember and what children desire. Tourism Management Perspectives 33: 1-11.

Falk JH and Dierking LD (2018) Learning from Museums (2nd ed). Lanham: Rowman \& Littlefield.

Frost $\mathrm{W}$ and Laing JH (2017) Children, families and heritage. Journal of Heritage Tourism 12(1): 1-6.

Graburn NH (1983) Editor's page. Annals of Tourism Research 10(1): 1-3.

Gutiérrez IT, Miller PJ, Rosengren KS, et al. (2014) III. Affective dimensions of death: Children's books, questions, and understandings. Monographs of the Society for Research in Child Development 79(1): 43-61. 
Hartmann, R (2014) Dark tourism, thanatourism, and dissonance in heritage tourism management: New directions in contemporary tourism research. Journal of Heritage Tourism 9(2): 166-182.

Hirsch CR and Holmes EA (2007) Mental imagery in anxiety disorders. Psychiatry 6(4): 161165.

Hunter SB and Smith DE (2008) Predictors of children's understandings of death: Age, cognitive ability, death experience and maternal communicative competence. OMEGA-Journal of Death and Dying 57(2): 143-162.

Israfilova F and Khoo-Lattimore C (2018) Sad and violent but I enjoyed it: Children's engagement with dark tourism as an educational tool. Tourism and Hospitality Research. Epub ahead of print 4 August 2018. DOI: 10.1177/1467358418782736.

Jackson M and Colwell J (2001) Talking to children about death. Mortality 6: 321-325.

Ji J, Anderson D, Wu X, et al. (2014) Chinese family groups' museum visit motivations: A comparative study of Beijing and Vancouver. Curator: The Museum Journal 57(1): 8196.

Kellett M (2005) Children as active researchers: A new research paradigm for the $21^{\text {st }}$ century? Available at: http://oro.open.ac.uk/7539/ (accessed 04 February 2020).

Kellett M (2010) Small shoes, big steps! Empowering children as active researchers. American Journal of Community Psychology 46(1): 195-203.

Kerr MM, Dugan SE and Frese KM (2016, July/August) Using children's artifacts to avoid interpretive missteps. Legacy: The Magazine of the National Association for Interpretation.

Kerr MM and Price RH (2016) Overlooked encounters: Young tourists' experiences at dark sites. Journal of Heritage Tourism 11(2): 177-185.

Kerr MM and Price RH (2018) "I know the plane crashed": Children's perspectives in dark tourism. In: Stone P, Hartmann R, Seaton T, et al. (eds) The Palgrave Handbook of Dark Tourism Studies. London: Palgrave Macmillan, pp.553-583.

Kerr MM, Fried SE, Price RH, et al. (2017) Rural children's responses to the Flight 93 crash on September 11, 2001. Journal of Rural Mental Health 41(3): 176-188.

Kerr MM, Price RH, Savine CD, et al. (2017) Interpreting terrorism: Learning from children's visitor comments. Journal of Interpretation Research 22(1). Available at: https://www.interpnet.com/NAI/nai/_publications/JIR_v21n1_Kerr.aspx.

Khoo-Lattimore C (2015) Kids on board: Methodological challenges, concerns, and clarifications when including young children's voices in tourism research. Current Issues in Tourism 18(9): 845-858.

King-McKenzie E (2011) Death and dying in the curriculum of public schools: Is there a place? Journal of Emerging Knowledge on Emerging Markets 3: 511-520.

Knudsen BT (2011) Thanatourism: Witnessing difficult pasts. Tourist Studies 11(1): 55-72.

Koocher GP, O’Malley JE, Foster D et al. (1976) Death anxiety in normal children and adolescents. Psychopathology 9(3-4): 220-229.

Kucan L, Cho BY and Han H (2017) Introducing the historical thinking practice of contextualizing to middle school students. The Social Studies 108(5): 210-218.

Laing J and Frost W (2013) Commemorative Events: Memory, Identities, Conflict. New York: Routledge.

Larsen S and Jenssen D (2004) The school trip: Travelling with, not to or from. Scandinavian Journal of Hospitality and Tourism 4(1): 43-57. 
Lazar A and Torney-Purta J (1991) The development of the subconcepts of death in young children: A short-term longitudinal study. Child Development 62(6): 1321-1333.

Lennon JJ and Foley M (2000) Dark Tourism: The Attraction of Death and Disaster. London: Continuum.

Light D (2017) Progress in dark tourism and thanatourism research: An uneasy relationship with heritage tourism. Tourism Management 61: 275-301.

Lovorn MG (2012) Historiography in the methods course: Training preservice history teachers to evaluate local historical commemorations. The History Teacher 45(4): 569-579.

McCabe S (2005) "Who is a tourist?" A critical review. Tourist Studies 5(1): 85-106.

McLean KC and Mansfield CD (2012) The co-construction of adolescent narrative identity: Narrative processing as a function of adolescent age, gender, and maternal scaffolding. Developmental Psychology 48(2): 436.

Mak MHJ (2011) Chinese secondary students' knowledge of, and attitudes toward, death, dying, and life education: A qualitative study. Illness, Crisis \& Loss 19(4): 309-327.

Marcus AS, Stoddard JD and Woodward WW (2012) Teaching History with Museums: Strategies for K-12 Social Studies. New York: Routledge.

Martini A and Buda DM (2020) Dark tourism and affect: framing places of death and disaster. Current Issues in Tourism 23(6): 679-692.

Matteucci X and Gnoth J (2017) Elaborating on grounded theory in tourism research. Annals of Tourism Research 65: 49-59.

Minnaert L (2014) Social tourism participation: The role of tourism inexperience and uncertainty. Tourism Management 40: 282-289.

Mooney S, Schänzel H and Poulston J (2017) Illuminating the blind spots. Hospitality and Society 7(2): 105-201.

Moscardo G, Ballantyne R and Hughes K (2007) Designing Interpretive Signs: Principles in Practice. Golden, CO: Fulcrum Publishing.

Nguyen SP and Gelman SA (2002) Four and 6-year olds' biological concept of death: The case of plants. British Journal of Developmental Psychology 20(4): 495-513.

Nguyen S and Rosengren K (2004) Parental reports of children's biological knowledge and misconceptions. International Journal of Behavioral Development 28(5): 411-420.

Noppe IC and Noppe LD (1997) Evolving meanings of death during early, middle, and later adolescence. Death Studies 21(3): 253-275.

Park H (2010) Heritage tourism: Emotional journeys into nationhood. Annals of Tourism Research 37(1): 116-135.

Patterson AR (2007) "Dad look, she's sleeping": Parent-child conversations about human remains. Visitor Studies 10(1): 55-72.

Penfold-Mounce R (2018) Death, the Dead and Popular Culture. Bingley: Emerald Publishing. Perkins KD and Mackey B (2008) Supporting grieving children in early childhood programs. Dimensions of Early Childhood 36(3): 13-19.

Pinter A and Zandian S (2014) "I don't ever want to leave this room": Benefits of researching "with" children. ELT Journal 68(1), 64-74.

Potts TJ (2012) "Dark tourism" and the "kitschification" of 9/11. Tourist Studies 12(3): 232-249. Poria Y and Timothy DJ (2014) Where are the children in tourism research? Annals of Tourism Research 47: 93-95. 
Poria Y, Atzaba-Poria N and Barrett M (2005) The relationship between children's geographical knowledge and travel experience: An exploratory study. Tourism Geographies 7(4): 389397.

Price RH (2018) Expectations and revelations: Children discuss conducting research during a multi-day school excursion. PhD Thesis, University of Pittsburgh, US.

Price RH and Kerr MM (2017) "'I thought it was cool how we were part of research': Engaging children as co-researchers on their school excursions." The Qualitative Report $8^{\text {th }}$ Annual Conference, Fort Lauderdale, FL, 12-14 January.

Price RH and Kerr MM (2018) Child's play at war memorials: Insights from a social media debate. Journal of Heritage Tourism 13(2): 167-180.

Prout A and James A (1997) A new paradigm for the sociology of childhood? Provenance, promise and problems. In: James A and Prout A (eds) Constructing and Reconstructing Childhood: Contemporary Issues in the Sociological Study of Childhood. London: Farmer Press, pp.7-32.

Roberts C (2018) Educating the (dark) masses: Dark tourism and sensemaking. In: Stone P, Hartmann R, Seaton T, Sharpley R et al. (eds) The Palgrave Handbook of Dark Tourism Studies. London: Palgrave Macmillan, pp.603-637.

Roberts C and Stone P (2014) Dark tourism and dark heritage: Emergent themes, issues and consequences. In: Convery I, Corsane G and Davis P (eds) Displaced Heritage: Responses to Disaster, Trauma and Loss. Woodbridge: The Boydell Press, pp.9-18.

Robinson M and Picard D (eds) (2012) Emotion in motion: Tourism, affect and transformation. Abington: Routledge.

Roche D and Quinn B (2017) Heritage sites and schoolchildren: Insights from the Battle of the Boyne. Journal of Heritage Tourism 12(1): 7-20.

Rosengren KS, Gutiérrez IT and Schein SS (2014) IV. Cognitive dimensions of death in context. Monographs of the Society for Research in Child Development 79(1): 62-82.

Ryan C (1992) The child as visitor. World Travel and Tourism Review 2: 135-139.

Schänzel H and Carr N (2015) Special issue on children, families and leisure - first of two issues. Annals of Leisure Research 18(2): 171-174.

Schänzel H and Carr N (2016) Children, Families and Leisure. New York: Routledge.

Schänzel H, Yeoman I and Backer E (2012) Family Tourism: Multidisciplinary Perspectives. Bristol: Channel View Publications.

Shaffer SE (2016) Engaging Young Children in Museums. New York: Routledge.

Sharpley R and Stone PR (2009) (Re)presenting the macabre: Interpretation, kitschification and authenticity. In: Sharpley R and Stone P (eds) The Darker Side of Travel: The Theory and Practice of Dark Tourism. Bristol: Channel View Publications, pp.109-128.

Shavanddasht M and Schänzel H (2019) Measuring adolescents' tourism satisfaction: The role of mood and perceived parental style. Tourism and Hospitality Research 19(3): 308-320.

Simon N (2009) Review of an exhibition: "The Power of Children." Available at: http://www.exhibitfiles.org/the_power_of_children (accessed 07 March 2019).

Small J (2008) The absence of childhood in tourism studies. Annals of Tourism Research 35(3): $772-789$.

Sofka CJ (1997) Social support "internetworks," caskets for sale, and more: Thanatology and the information superhighway. Death Studies 21(6): 553-574. 
Sofka CJ (2009) Adolescents, technology, and the internet: Coping with loss in the digital world. In: Balk D and Corr C (eds) Adolescent Encounters with Death, Bereavement, and Coping. New York: Springer, pp.155-173.

Speece MW and Brent SB (1984) Children's understanding of death: A review of three components of a death concept. Child Development 55(5): 1671-1686.

Stevens Q and Franck KA (2015) Memorials as spaces of engagement: Design, use and meaning. New York: Routledge.

Stone PR (2006) A dark tourism spectrum: Towards a typology of death and macabre related tourist sites, attractions and exhibitions. Tourism: An Interdisciplinary International Journal 54(2): 145-160.

Stone PR (2011) Dark tourism: Towards a new post-disciplinary research agenda. International Journal of Tourism Anthropology 1(3/4): 318-332.

Stone PR (2012) Dark tourism and significant other death: Towards a model of mortality mediation. Annals of Tourism Research 39(3): 1565-1587.

Stone PR, Hartmann R, Seaton T, et al. (eds) (2018) The Palgrave Handbook of Dark Tourism Studies. London: Palgrave Macmillan.

Stone PR and Sharpley R (2008) Consuming dark tourism: A thanatological perspective. Annals of Tourism Research 35(2): 574-595.

Sutcliffe K and Kim S (2014) Understanding children's engagement with interpretation at a cultural heritage museum. Journal of Heritage Tourism 9(4): 332-348.

Swarbrooke J and Horner S (1999) Consumer Behaviour in Tourism. Oxford: ButterworthHeinemann.

Tagg S and Seaton AV (1994) How different are Scottish family holidays from English? In: Seaton A (ed) Tourism: The State of the Art. Chichester: John Wiley \& Sons, pp.540548.

Urry J and Larsen J (2011) The Tourist Gaze 3.0. Thousand Oaks: Sage.

Veal AJ (2017) Research Methods for Leisure and Tourism. London: Pearson.

Virgili S, Delacour H, Bornarel F, et al. (2018) "From the Flames to the Light": 100 years of the commodification of the dark tourist site around the Verdun battlefield. Annals of Tourism Research 68: 61-72.

Walby K and Piché J (2015) Staged authenticity in penal history sites across Canada. Knudsens 15(3): 231-247.

Walter T (2004) Body worlds: Clinical detachment and anatomical awe. Sociology of Health \& Illness 26(4), 464-488.

Walter T (2009) Dark tourism: Mediating between the dead and the living. In: Sharpley R and Stone P (eds) The Darker Side of Travel: The Theory and Practice of Dark Tourism. Bristol: Channel View Publications, pp.39-55.

Woodhead M (2008) Childhood studies: Past, present and future. In: Kehily M (ed) An Introduction to Childhood Studies. London: Open University Press, pp.17-31.

Wu MY and Wall G (2017) Visiting heritage museums with children: Chinese parents' motivations. Journal of Heritage Tourism 12(1): 36-51. 